\title{
Phototactic behavior 10: phototactic behavioral effects of Plodia interpunctella (Hübner) (Lepidoptera: Pyralidae) adults to different light-emitting diodes of seven wavelengths
}

\author{
Jun-Hwan Park ${ }^{1}$. Hoi-Seon Lee ${ }^{1}$ (D)
}

Received: 16 January 2016 / Accepted: 12 February 2016 / Published Online: 30 June 2016

(C) The Korean Society for Applied Biological Chemistry 2016

\begin{abstract}
Phototactic behavioral responses of the Indian meal moth, Plodia interpunctella (Hübner), adults were determined to different light-emitting diodes (LEDs) of seven wavelengths, and their behavioral responses were compared to that using a commercial luring lamp (BLB) under laboratory conditions. Based on the attractive responses under optimal light conditions (60 lx luminance intensity and $30 \mathrm{~min}$ light exposure time), the green LED (520 \pm 5 $\mathrm{nm})$ showed the highest attractive rate $(520 \pm 5 \mathrm{~nm}, 52.2 \%)$, followed by the blue LED $(470 \pm 10 \mathrm{~nm}, 33.9 \%)$, the yellow LED (590 $\pm 5 \mathrm{~nm}, 32.2 \%)$, BLB (28.9\%), UV LED (365 nm, $22.8 \%)$, the red LED $(625 \pm 10 \mathrm{~nm}, 14.5 \%)$, the white LED (450-620 nm, $10.6 \%$ ), and IR LED (730 nm, $9.5 \%$ ). In addition, the green LED to $P$. interpunctella adults was approximately 1.81 times more attractive than BLB. These results indicate that the green LED could be most useful for monitoring of $P$. interpunctella adults.
\end{abstract}

Keywords Light-emitting diodes $\cdot$ Light exposure time $\cdot$ Luminous intensity $\cdot$ Phototactic behavioral responses $\cdot$ Plodia interpunctella

\section{Introduction}

The insect control of stored food product is very important to maintain the quality of foods/grains. This is particularly true in grain storages and food processing plants, where detection of an insect infestation in foods/grains for human consumption can

Hoi-Seon Lee $(\bowtie)$

E-mail: hoiseon@jbnu.ac.kr

${ }^{1}$ Department of Bioenvironmental Chemistry, College of Agriculture \& Life Science, Chonbuk National University, Jeonju 54896, Republic of Korea

This is an Open Access article distributed under the terms of the Creative Commons Attribution Non-Commercial License (http://creativecommons. org/licenses/by-nc/3.0/) which permits unrestricted non-commercial use, distribution, and reproduction in any medium, provided the original work is properly cited. accrue enormous losses for the producer (Phillps, 2006; Kishan et al. 2008). The Indian meal moth, Plodia interpunctella (Lepidoptera: Pyralidae), is a wide-spread insect pests of stored grains and value-added food products (Zhu et al. 1999; Nansen and Phillips 2004). The $P$. interpunctella adults attack stored food/grain products of different nutritional values and physical condition and development is mainly affected by the diet upon which it feeds during the larval stage (Lecato 1976; $\mathrm{Na}$ and Ryoo 2000). $P$. interpunctella larvae can invade packaged foods and feed on a wide diversity of foods such as cereals, nuts, dried fruits, and some spices (Na and Ryoo 2000; Sauer and Shelton 2002; PerezMendoza and Aguilera-Peña 2004). Current pest management of the stored foods/grains has depended on the use of chemicals, such as chlorfluazuron and methyl bromide (Mohandassa et al. 2007; Ebadollahi et al. 2010). Methyl bromide is commonly used fumigant in the management of the stored-product pests. However, Montreal Protocol, an international agreement (Anonymous 2004) will certainly further affect management for $P$. interpunctella, accelerating the demand for effective control strategies (Phillips et al. 2000). Recently LED traps are extensively used to control insect pests (Zheng et al. 2014). LEDs have some advantage including low temperature, small size, low cost, sensitivity, high reliability, and long operating life time (Chen et al. 2004; Jeon et al. 2014). Therefore, the aim of our study was to determine the phototactic behavior of $P$. interpunctella adults in response to LED, and it was compared with that of a commercial BLB.

\section{Materials and Methods}

\section{Stored insect pest}

A culture of Indian meal moth adults was obtained from the National Academy of Agricultural Science, RDA (Korea). They were reared on an artificial diet consisting of $480 \mathrm{~g}$ corn meal, $120 \mathrm{~g}$ flour, and $70 \mathrm{~mL}$ glycerol. The culture was maintained at 
$65 \pm 4 \%$ relative humidity (RH), $27 \pm 2{ }^{\circ} \mathrm{C}$, and a $14 \mathrm{~h}$ light $/ 10 \mathrm{~h}$ dark photoperiod.

\section{Light source and test chamber}

The light sources were produced by Kodenshi Auk Co. Ltd (Korea). The types of LEDs used in our study as follow: UV LED (365 nm), blue LED (CL-1 W-UBB, 15.0 $\pm 3.1 \mathrm{~lm}, 470 \pm 10 \mathrm{~nm}$ ), green LED (CL-1 W-UPGB, $45.0 \pm 3.5 \mathrm{~lm}, 520 \pm 5 \mathrm{~nm}$ ), yellow LED (PP592-8L61-AOBI, 40.0 $\pm 10.0 \mathrm{~lm}, 590 \pm 5 \mathrm{~nm}$ ), red LED (CL-1 W-UBB, $350.0 \pm 1.2 \mathrm{~lm}, 625 \pm 10 \mathrm{~nm}$ ), white (CL-1W-URB, $450-620 \mathrm{~nm})$, and IR LED $(730 \mathrm{~nm})$. The LED modules board $(70 \times 140 \mathrm{~mm})$ is composed of 40 LEDs of each color and was attached to a control circuit board $(300 \times 150 \mathrm{~mm})$ in the chamber. The phototactic behavioral responses of $P$. intrepunctella adults were compared with those to a BLB (315-400 nm, F8T5 BLB: Sankyo-Denki Co. Ltd., Tokyo, Japan), which served as a control. The phototactic test chamber for analyzing the phototactic behavioral responses of $P$. interpunctella adults was designed by $\mathrm{Oh}$ and Lee (2010). The test chamber consisted of an opaque acrylic body $(500 \times 1,500 \times 300 \mathrm{~mm})$ and two transparent acrylic walls that were fitted inside on both ends of the test chamber. An insect entrance hole $(100 \mathrm{~mm}$ in diameter, covered with nylon fishnet cloth) was placed at a point between the light arm and the dark. The experiments were conducted in a chamber kept at $27 \pm 2{ }^{\circ} \mathrm{C}$ and $65 \pm 4 \% \mathrm{RH}$ in darkness.

\section{Bioassay}

The phototactic behavioral responses of $P$. intrepunctella adult were measured under different light conditions, such as different luminance intensities, wavelengths, and light durations. The luminance intensities of the LEDs was measured using an illuminometer (LM-322; AS ONE Co. Ltd., Osaka, Japan) positioned $700 \mathrm{~mm}$ from the light source. Thirty $P$. intrepunctella adults were collected using aspirator and were released into the insect entrance hole of chamber. The behavioral responses of $P$. intrepunctella adults to LEDs were evaluated by counting the number of located insects in the 'light' and 'dark' zone of the chamber. These results were compared with those of BLB. Attractive rate $(\%)=($ A number of $P$. intrepunctella adults in a rage of $500 \mathrm{~mm}$ from light sources/total $P$. intrepunctella $) \times 100$. All experiments were repeated at least five times. The statistical analysis was performed by analysis of variance (ANOVA) to compare the number of $P$. intrepunctella adults attracted to each LED using SPSS ver. 18.0 software (SPSS Inc., Chicago, IL, USA). Results are expressed as mean $\pm \mathrm{SE}$ (standard error).

\section{Results and Discussion}

To evaluate the behavioral responses of $P$. intrepunctella adults to the LEDs, the attractive effects to seven monochromatic light, five luminous intensities, and light exposure times were compared to that of a BLB, which served as a positive control. The attractive rate of $P$. intrepunctella adults to five (blue, green, yellow, red, and white) LEDs under five luminous intensities (20, 40, 60, 80, and $100)$ are shown in Table 1 . The blue $(470 \pm 10 \mathrm{~nm})$, green $(520 \pm 5$ $\mathrm{nm})$, yellow $(590 \pm 5 \mathrm{~nm})$, red $(625 \pm 10 \mathrm{~nm})$, and white $(450-620$ $\mathrm{nm})$ LEDs showed the highest attractive response at $60 \mathrm{~lx}(33.9$, $52.2,32.2,14.5$, and $10.6 \%$, respectively). Basic on the test results of luminance intensities, the attractive responses of $P$. intrepunctella adults to varying time of light exposure $(10,20,30,40,50$, and 60 min) were investigated with the seven LEDs (UV, blue, green, yellow, red, white, and IR LEDs) (Table 2). At 30 min exposure time, all light sources were highly attractive to $P$. intrepunctella adults; the percentage of attracted $P$. intrepunctella adults declined with increasing exposure time. The attractive effects of LEDs was investigated under optimal light conditions (60 lx luminance intensity and $30 \mathrm{~min}$ light exposure time), and were compared with that of a BLB (Table 3). Under optimal light conditions, the green LED $(520 \pm 5 \mathrm{~nm}, 52.2 \%)$ was the most attractive to $P$. intrepunctella adults, followed by blue LED $(470 \pm 10 \mathrm{~nm}, 33.9 \%)$, yellow LED ( $590 \pm 5 \mathrm{~nm}, 32.2 \%)$, BLB (28.9\%), UV LED (365 $\mathrm{nm}, 22.8 \%)$, red LED $(625 \pm 10 \mathrm{~nm}, 14.5 \%)$ white LED (450$620 \mathrm{~nm}, 10.6 \%)$, and IR LED (730 nm, $9.5 \%)$. The attractive effects of green, blue, and yellow LED were approximately 1.11 to 1.81 times higher to $P$. intrepunctella adults than those of a BLB, which is used in commercial electric traps. Previous studies on the electroretinogram have demonstrated that $P$. intrepunctella

Table 1 Attractive rate of $P$. intrepunctellaadultsto five LEDsunder various luminance intensities $(\mathrm{lx})^{1)}$

\begin{tabular}{|c|c|c|c|c|c|}
\hline \multirow{3}{*}{ Wavelength (color) } & \multicolumn{5}{|c|}{ Attractive rate $(\%)^{2)}$} \\
\hline & \multicolumn{5}{|c|}{ Luminance intensity (lx) } \\
\hline & 20 & 40 & 60 & 80 & 100 \\
\hline $470 \pm 10 \mathrm{~nm}$ (Blue) & $7.2 \pm 0.67^{\mathrm{c}}$ & $9.4 \pm 0.81^{\mathrm{c}}$ & $33.9 \pm 1.84^{\mathrm{ab}}$ & $8.9 \pm 0.71^{\mathrm{c}}$ & $22.2 \pm 1.47^{\mathrm{bc}}$ \\
\hline $520 \pm 5 \mathrm{~nm}$ (Green) & $17.2 \pm 1.42^{\mathrm{bc}}$ & $20.6 \pm 1.39^{\mathrm{bc}}$ & $52.2 \pm 2.14^{\mathrm{a}}$ & $45.0 \pm 1.97^{\mathrm{a}}$ & $26.1 \pm 1.68^{\mathrm{ab}}$ \\
\hline $590 \pm 5$ nm (Yellow) & $3.9 \pm 0.47^{\mathrm{c}}$ & $5.6 \pm 0.52^{\mathrm{c}}$ & $32.2 \pm 1.77^{\mathrm{ab}}$ & $7.8 \pm 0.74^{\mathrm{c}}$ & $21.4 \pm 1.34^{\mathrm{bc}}$ \\
\hline $625 \pm 10 \mathrm{~nm}(\mathrm{Red})$ & $10.6 \pm 1.08^{\mathrm{c}}$ & $11.1 \pm 1.14^{\mathrm{c}}$ & $14.5 \pm 1.57^{\mathrm{bc}}$ & $12.8 \pm 1.32^{b c}$ & $6.1 \pm 0.55^{\mathrm{c}}$ \\
\hline 450-620 nm (white) & $1.7 \pm 0.24^{\mathrm{c}}$ & $5.0 \pm 0.38^{\mathrm{c}}$ & $10.6 \pm 1.11^{\mathrm{c}}$ & $2.2 \pm 0.27^{\mathrm{c}}$ & $2.8 \pm 0.31^{\mathrm{c}}$ \\
\hline
\end{tabular}

${ }^{1)}$ Each value is the average of 6 determinations after a 30 min exposure, with 30 adult insects per replication

${ }^{2)}$ Attractive rate (\%) is the average percentage of the 30 P. interpunctellaadults attracted to various light intensities 
Table 2 Attractive rate of $P$. intrepunctellaadults to seven LEDs at various light exposure times $(\mathrm{h})^{1)}$

\begin{tabular}{|c|c|c|c|c|c|c|}
\hline \multirow{3}{*}{ Wavelength (color) ${ }^{3)}$} & \multicolumn{6}{|c|}{ Attractive rate $(\%)^{2)}$} \\
\hline & \multicolumn{6}{|c|}{ Light exposure time (min) } \\
\hline & 10 & 20 & 30 & 40 & 50 & 60 \\
\hline $365 \mathrm{~nm}$ (UV) & $9.4 \pm 1.07^{\mathrm{c}}$ & $20.6 \pm 1.48^{\mathrm{bc}}$ & $22.8 \pm 1.46$ & $18.9 \pm 1.43^{\mathrm{bc}}$ & $19.4 \pm 1.73^{\mathrm{bc}}$ & $18.3 \pm 1.44^{\mathrm{bc}}$ \\
\hline $470 \pm 10 \mathrm{~nm}$ (Blue) & $31.1 \pm 1.67^{\mathrm{ab}}$ & $31.7 \pm 1.69^{\mathrm{ab}}$ & $33.9 \pm 1.87^{\mathrm{ab}}$ & $26.1 \pm 1.75^{\mathrm{ab}}$ & $24.4 \pm 1.62^{\mathrm{bc}}$ & $22.8 \pm 1.91^{\mathrm{bc}}$ \\
\hline $520 \pm 5 \mathrm{~nm}($ Green $)$ & $31.7 \pm 1.79^{\mathrm{ab}}$ & $22.8 \pm 1.74^{\mathrm{bc}}$ & $52.2 \pm 2.18^{\mathrm{a}}$ & $35.6 \pm 1.84^{\mathrm{ab}}$ & $30.0 \pm 1.62^{\mathrm{ab}}$ & $21.1 \pm 1.37^{\mathrm{bc}}$ \\
\hline $590 \pm 5 \mathrm{~nm}$ (Yellow) & $20.6 \pm 1.57^{\mathrm{bc}}$ & $26.1 \pm 1.77^{\mathrm{ab}}$ & $32.2 \pm 1.73^{\mathrm{ab}}$ & $25.6 \pm 1.66^{\mathrm{bc}}$ & $24.4 \pm 1.41^{b c}$ & $19.4 \pm 1.52^{\mathrm{bc}}$ \\
\hline $625 \pm 10 \mathrm{~nm}(\mathrm{Red})$ & $3.8 \pm 0.44^{\mathrm{c}}$ & $5.0 \pm 0.51^{\mathrm{c}}$ & $14.5 \pm 1.57^{\mathrm{bc}}$ & $4.4 \pm 0.43^{\mathrm{c}}$ & $3.8 \pm 0.66^{\mathrm{c}}$ & $2.8 \pm 0.38^{\mathrm{c}}$ \\
\hline 450-620 nm (white) & $6.1 \pm 0.74^{\mathrm{c}}$ & $8.9 \pm 0.88^{\mathrm{c}}$ & $10.6 \pm 1.27^{\mathrm{c}}$ & $10.0 \pm 1.27^{\mathrm{c}}$ & $8.9 \pm 0.83^{\mathrm{c}}$ & $9.4 \pm 1.08^{\mathrm{c}}$ \\
\hline $730 \mathrm{~nm}$ (IR) & $4.4 \pm 0.53^{c}$ & $7.2 \pm 0.79^{\mathrm{c}}$ & $9.4 \pm 1.22^{\mathrm{c}}$ & $7.8 \pm 0.96^{\mathrm{c}}$ & $3.9 \pm 0.41^{\mathrm{c}}$ & $5.0 \pm 0.58$ \\
\hline
\end{tabular}

${ }^{1)}$ Each value is the average of 6 determinations after a 30 min exposure, with 30 adult insects per replication

${ }^{2)}$ Attractive rate $(\%)$ is the average percentage of the $30 \mathrm{P}$. interpunctellaadults attracted to light-exposure time

${ }^{3)}$ Each value is the average of 6 determinations per each light-exposure time at $8 \mathrm{~W}$ or $60 \mathrm{~lx}$

Table 3 Attractive rate of $P$. intrepunctellaadultsto seven LEDsand a BLB under optimal conditions ${ }^{1)}$

\begin{tabular}{|c|c|c|c|c|}
\hline \multirow{2}{*}{ Wavelength (color) $)^{2)}$} & \multicolumn{2}{|c|}{ Number of insect $($ Mean \pm SE) } & \multirow{2}{*}{ Attractive rate $(\%)^{3)}$} & \multirow{2}{*}{ Relative attraction $^{4)}$} \\
\hline & Light choice & No choice & & \\
\hline $365 \mathrm{~nm}$ (UV) & $6.83 \pm 1.03^{\mathrm{bc}}$ & $18.83 \pm 1.79$ & $22.8^{\mathrm{bc}}$ & 0.79 \\
\hline $470 \pm 10$ nm (Blue) & $10.17 \pm 1.37^{\mathrm{ab}}$ & $6.67 \pm 1.19$ & $33.9^{\mathrm{ab}}$ & 1.17 \\
\hline $520 \pm 5$ nm (Green) & $15.67 \pm 1.62^{\mathrm{a}}$ & $6.33 \pm 1.14$ & $52.2^{\mathrm{a}}$ & 1.81 \\
\hline $590 \pm 5 \mathrm{~nm}($ Yellow) & $9.67 \pm 1.24^{\mathrm{ab}}$ & $11.83 \pm 1.44$ & $32.2^{\mathrm{ab}}$ & 1.11 \\
\hline $625 \pm 10 \mathrm{~nm}(\mathrm{Red})$ & $4.33 \pm 0.67^{\mathrm{bc}}$ & $20.83 \pm 1.82$ & $14.5^{\mathrm{bc}}$ & 0.50 \\
\hline 450-620 nm (white) & $3.17 \pm 0.51^{\mathrm{bc}}$ & $14.67 \pm 1.23$ & $10.6^{\mathrm{c}}$ & 0.37 \\
\hline $730 \mathrm{~nm}(\mathrm{IR})$ & $2.83 \pm 0.47^{\mathrm{c}}$ & $5.67 \pm 0.69$ & $9.5^{\mathrm{c}}$ & 0.32 \\
\hline BLB & $8.67 \pm 1.19^{\mathrm{bc}}$ & $20.33 \pm 1.84$ & $28.9^{\mathrm{b}}$ & 1.00 \\
\hline
\end{tabular}

${ }^{1)}$ Each value is the average of 6 determinations at optimal conditions (60 lx and $30 \mathrm{~min}$ ), with 30 adult insects per replication

${ }^{2)}$ Each value is the average of 6 determinations per each light-exposure time at $8 \mathrm{~W}$

${ }^{3)}$ Attractive rate $(\%)$ is the average percentage of the 30 P. interpunctellaadults attracted to light-exposure time

${ }^{4)}$ Relative attraction $=$ attractive rate of each wavelength/attractive rate of BLB

eyes respond to blue $(450 \mathrm{~nm})$ and green $(550 \mathrm{~nm})$ wavelengths range, with the greatest responses to green light (Marzke et al. 1973; Kishan et al. 2008; Cowan and Gries 2009). Moreover, behavioral studies have demonstrated by Stremer (1959) that $P$. intrepunctella adults showed the highest attractive effect to UV $(365 \mathrm{~nm})$ and green $(580 \mathrm{~nm})$ lights. In our study, the green LED was more attractive than blue and UV LEDs to $P$. intrepunctella adults. These results contrast with those suggested by Cowan and Gries (2009) that the blue light is more attractive than green light to $P$. intrepunctella adults (both of males and gravid females). These contrasting results may be connected with difference of experiment designs. Contrary to our experiment design, Cowan and Gries (2009) in choice experiments tested the blue, green, orange, and red light as 2- or 4-choice test stimuli at $15 \mu \mathrm{W} / \mathrm{cm}^{2}$.

Previous studies have reported that the attractive effect of the green LED to insect pests. For example, Nakamoto and Kuba (2004) reported that the green LED (536 nm) was more attractive than blue LED $(470 \mathrm{~nm})$ to West Indian sweet potato weevils (females) in a sweet potato field. In addition, Chen et al. (2004) reported that the yellow sticky card (YC) equipped with lime green LED $(530 \mathrm{~nm})$ traps captured more leafhoppers and western flower thrips than YC in greenhouse. Taken together, the results of our study indicate that light traps equipped with the green LED $(520 \pm 5 \mathrm{~nm})$ could be a new control strategy against $P$. intrepunctella adults. However, further research is needed to control of $P$. intrepunctella adults in a broad range of granary conditions to find methods for increasing the efficiency.

Acknowledgments This work was carried out with the support of "Cooperative Research Program for Agriculture Science \& Technology Development (Project title: Development of integrated pest management techniques using natural products and LEDs in the grain storage, Project No. PJ01004501)" Rural Development Administration, Republic of Korea.

\section{References}

Anonymous (2004) Notice of proposed rulemaking-protection of stratospheric ozone: process for exempting critical uses from the phaseout of methyl bromide. Federal Register 69: 55365-55402

Chen TY, Chu CC, Henneberry TJ, Umeda K (2004) Monitoring and trapping insects on poinsettia with yellow sticky card traps equipped with lightemitting diodes. Hort Technol 14: 337-341

Cowan T, Gries G (2009) Ultraviolet and violet light: attractive orientation cues for the Indian meal moth, Plodia interpunctella. Entomol Exp Appl 
58: $359-363$

Ebadollahi A, Safaralizadeh MH, Hoseini SA, Ashouri S, Sharifian I (2010) Insecticidal activity of essential oil of Agastache foeniculum against Ehestia kuehniella and Plodia interpunctella (Lepidoptera: Pyralidae). Mun Ent Zool 5: 785-791

Jeon JH, Kim MG, Lee HS (2014) Phototactic behavior 4: attractive effects of Trialeurodes vaporariorum adults to light-emitting diodes under laboratory conditions. J Korean Soc Appl Biol Chem 57: 197-200

Kishan R, Sambaraju KR, Phillips TW (2008) Responses of adult Plodia interpunctella (Hübner) (Lepidoptera: Pyralidae) to light and combinations of attractants and light. J Insect Behav 21: 422-439

Lecato GL (1976) Yield, development, and weight of Cadra cautella (Walker) and Plodia interpunctella (Hübner) on twenty one diets derived from natural products. J Stored Prod Res 12: 43-47

Marzke FO, Street MW, Mullen MA, McCray TL (1973) Spectral responses of six species of stored-product insects to visible light. J Georgia Entomol So 8: 195-200

Mohandassa S, Arthur FH, Zhu KY, Throne JE (2007) Biology and management of Plodia interpunctella (Lepidoptera: Pyralidae) in stored products. J Stored Prod Res 43: 302-311

Na JH, Ryoo MI (2000) The influence of temperature on development of Plodia interpunctella (Lepidoptera: Pyralidae) on dried vegetable commodities. J Stored Prod Res 36: 125-129

Nakamoto Y, Kuba H (2004) The effectiveness of a green light emitting diode (LED) trap at capturing the West Indian sweet potato weevil, Euscepes postfasciatus (Fairmaire) (Coleoptera: Curculionidae) in a sweet potato field. Appl Entomol Zool 39: 491-495

Nansen C, Phillips TW (2004) Attractancy and toxicity of attracticide for Indianmeal moth, Plodia interpunctella (Lepidoptera: Pyralidae). Ann Entomol Soc Am 91: 703-710

Oh MS, Lee HS (2010) Development of phototactic test apparatus equipped with light source for monitoring pests. J Appl Biol Chem 53: 248-252

Perez-Mendoza J, Aguilera-Peña M (2004) Development, reproduction, and control of the Indian meal moth, Plodia interpunctella (Hübner) (Lepidoptera: Pyralidae), in stored seed garlic in Mexico. J Stored Prod Res 40: 409-421

Phillips TW, Berbert RC, Cuperus GW (2000) Post-harvest integrated pest management. In: Francis, FJ (ed) Encyclopedia of Food Science and Technology. $2^{\text {nd }}$ edn. Wiley, New York, pp 2690-2701

Sauer JA, Shelton MD (2002) High-temperature controlled atmosphere for post-harvest control of Indian meal moth (Lepidoptera: Pyralidae) on preserved flowers. J Econ Entomol 95: 1074-1078

Stremer RA (1959) Spectral response of certain stored-product insects to electromagnetic radiation. J Econ Entomol 52: 888-892

Zheng LX, Zheng Y, Wu WJ, Fu YG (2014) Field evaluation of different wavelengths light emitting diodes as attractants for adult Aleurodicus dispersus Russell (Hemiptera: Aleyrodidae). Neotrop Entomol 43: 409_ 414

Zhu J, Ryne C, Unelius CR, Valeur PG, Löfstedt C (1999) Reidentification of the female sex pheromone of the Indian meal moth, Plodia interpuctella: evidence for a four component pheromone blend. Entomol Exp Appl 92: $137-146$ 